\title{
Analysis on the Environmental Cost of Logistics Activity
}

\author{
Jicheng Xing \\ Luojia College, Wuhan University, Wuhan430000, China. \\ jasooon@126.com
}

Keywords: Logistics activities, Logistics environmental cost,Environmental value.

\begin{abstract}
Natural resources and natural environment is the material basis of human survival,development and enjoyment, but for a long time its value has been underestimated or evenignored. This paper tries to reflect the loss of value of the resources and the environment in the logistics costs by way of cost accounting, and to promote the enterprise and society pay more attention to the comprehensive benefits of logistics activities. Specifically, thispaperdefines the concept of logistics activities environment cost, including resource consumption cost, environmental degradation cost and environmental related cost. And it considers calculating the cost of reducing consumption of resources using User Cost Approach, calculating the cost of maintenance way environmental degradation cost using Maintain Cost Method and estimating the environmental risk loss using risk loss ratio. This paper also discusses the significance of logistics environmental cost.
\end{abstract}

\section{Introduction}

Logistics activities associate production and consumption, and it is a wide range of economic activities existed in enterprises ubiquitously. Logistics activities create valuelike other production activities, but not increase the value of logistics objects generally. Besides, logistics process also consumes a lot of labor power, money, material and other resources, and it will emitharmful substances [1]. These characteristics of logistics activities lead to the special characteristics of its cost structure and calculation, to study logistics activities and understand the formation mechanism and content of its cost, is the premise of sustainable development of logistics industry.

Logistics cost problem is the core problem of enterprise and social economic management, and strengthening logistics cost management is an important measure to improve the profit margin of enterprises [2]. As for enterprise, calculating its logistics environment cost is not to increase the logistics cost, but to evaluate and control logistics activity performance more comprehensively from economic point of view, and prompt enterprise to make more responsible decision for the natural environment.

This paper makes analysis on the environmental cost of logistics activity. In this paper, the concept of logistics activities environment cost is defined and its calculation method is also discussed.

\section{Definition of logistics environment cost}

The environmental influence of logistics activities is objective and cannot be negligible; it is produced by consumption of resources and pollution in the logistics activities. However, we have neglected this influence and never use economic way to measure it for a long time. So clarifying the existence of environmental impact of logistics activities, defining the scope and content of environmental impact and assessing the size of the environmentimpact become the premise of controlling logistics cost and effective management [3].Economic measurement for environmental impact of logistics activities, called logistics environment cost in this paper, it is defined as follows:

Logistics environment cost is resources and environmental degradation effect caused by the consumption of non-renewable natural resources and emissions of pollutants in logistics activities, as well as related cost of preventing and reducing the effect, which consists of resource 
consumption cost, environmental degradation cost and environmental related costthree part.

Resource-consumption reducing cost is the consumption of non-renewable natural resources such as coal, oil and natural gas; environmental degradation cost is exhaust, noise, waste water,radiation and dust produced in logistics activities; environmental related cost is the environment related costs in logistics operation process, including environmental control cost, environmental insurance cost and environmental risk cost.

\section{Calculation steps of logistics environment cost}

In modern logistics, the circulation of material depends on the transportation system. That is, combine road, railway, water transport, aviation and pipeline and other transport modes organically to meet the needs of circulation, while minimize the total cost of the system (including time cost, value added service cost and environmental cost) to the lowest level. It can clearly be seen that transportation is not only the main part of the logistics activity, but also the main source of logistics cost. The calculation steps of each component of the logistics environment cost are introduced respectively as follows.

\subsection{Resource consumption cost}

As for non-renewable natural resources consumed by logistics activities, we use User Cost Approach to determine the resource consumption cost of logistics activities.

In accordance with the requirements of User Cost Approach, the data first need to determine is the annual return of non-renewable natural resourcesexploited this year, and the data are adjusted by the price of international coal, oil and natural gas.

Then we need to determine discount rate (interest rate)r.User cost discount rate of non-renewable natural resources is affected by risk-free interest rate and risk return, so we should consider both the interest rate and the industry profit margin when we determine the discount rate. In order to avoid high discount rate cause "resources first to die out" decision, we should coordinate the relative levels of various discount rates by macro-control way to ensure sustainable development. In addition, user cost is very sensitive to the discount rate, the relative level of discount rate will affect the utilization of natural resources.According to the knowledge of welfare economics, when the discount rate is greater than zero, the present value of assets is higher than the value of those in the future, thus result in assets of last generation depreciating and being unfavorable to next generation. So when we calculateresource consumption cost, it is very important to examine the low discount rate in User Cost Approach, because high discount rate will be beneficial tothe income of current generation and unfavorable to the income of future generation [4].

Finally, compare the coal, oil and gas user costs calculated theoretically with current resource tax and resource compensation fee, the difference is the resource consumption cost produced by using these resources.

\subsection{Environmental degradation cost}

Logistics activity will consume energy resources, meanwhile it will emit various kinds of substances which are harmful to the environment, such as automobile exhaust, noise, waste water and so on, and it will produce electromagnetic radiation and dust in some functional links, all these will cause the degradation of ecological environment. In the transport link which has greatest impact on the environment, different transportation way has different environmental influence on the mode and extent [5].

At present, it is difficult to include all of these damages when estimating environmental degradation cost. So here is the estimation principle: select environmental impact which causes serious pollution, whichhascertain statistical data and generally acceptedbasic information, and then, simplify calculationas much as possible. In practical applications, pollutant discharge standardscan be issued by the official, to meet the requirements of practicality and comparability.

As for environmental value loss caused by the discharge of pollutants, here we use Maintain Cost Method to calculateit. That is, after getting pollutants' emission quantity and unit management cost by related material, calculate the environmental degradation cost by formula, in which the determination of the pollutant unit management cost is difficult, because the different treatment 
methods for different objects can lead to huge deviation in the pollutant unit management cost.

\subsection{Environmental related cost}

Environmental related cost consists of environmental control cost, environmental insurance cost and environmental risk cost, in which environmental control costusually included in other costs, only need to simply peel and re-determine the ownership, so here does not involve the calculation of the content.

Due to the presence of uncertainty, breakage, loss or improper disposal of goods may happen during the process of circulation. Once the toxic and harmful substances leakage and other environmental pollution accident happen, it will cause immeasurable damage to the ecological environment, this kind of environmental damage is reflected as environmental risk cost in the logistics cost.In terms of logisticsrange, environmental risk loss may occur at all stages. From an operational point of view, this paper does not consider the potential impact and indirect effects of pollution accidents on the ecological environment, we only regard the environmental direct loss estimated by Maintain Cost Method or environmental pollution compensation as environmental risk cost, such environmental risk cost can be regarded as the minimum value of the risk of environmental damage [6].

Through the analysis of environmental accident damage and its responsibility subject, we can know that environmental risk loss and the industry and geographical position of environmental responsibility subject is closely related to management level, the difference of the environmental risks of different subject is obvious.Environmental risk cost can be calculated according to the statistics of the calendar year.

Environmental risk cost can also be estimated by the environmental risk loss rate at the beginning of the accounting period, then adjust it according to the fact at the end of the accounting period, in order to make environmentalresponsibility subject easy to carry on environmental risk control and evaluation. In this paper, environmental risk loss rate is defined as the proportionof environmental risk loss getting from historical statistics to the sum of resource consumption cost and environmental degradation cost. In the long run, this proportion should distinguish between industry, geographical position and development level to determine, and issue by industry association or government departmentperiodically.

Environmental insurance cost is the cost of insuring the environmental liability insurance, for such expenses we only need to confirm the ownership and to charge in accordance with the accounting method. Environmental liability insurance is gradually hive offfrom the public liability insurance and the third party liability insurance, along with the frequent occurrence of environmental pollution accident and the environmental tort action as well as the growing awareness of public environmental rights. Environmental pollution is usually referred to the phenomenon that due to theintervention of material and energy, the chemical, physical, biological or radioactive properties of environment has changed, so as to affect the environment function and the effective use of resources or endanger human health and human life. Environmental liability insurance is a special part of the whole system of liability insurance, also is a kind of ecological insurance. That is, applicant pass the risk of sudden, unexpected risk of malignant pollution or cumulative environmental liability risk on to insurance company, in the way of paying insurance premium to the insurer.

\section{Conclusions}

The rapid development of the logistics industry has brought huge economic benefits to the society, at the meantime; it leads to a large number of energy consumption and serious environmental pollution, causing environmental damage. This paper defines the concept of logistics activities environment cost, including resource consumption cost, environmental degradation cost and environmental related cost. And it considers calculating the cost of reducing consumption of resources by User Cost Approach, calculating the cost of maintenance way and environmental degradation cost by Maintain Cost Method and estimating the environmental risk loss using risk 
loss ratio.

\section{References}

[1]Paul R.Murphy and Richard R Poist.Green Perspectives and Practices:A "Comparative Logistics" Study.Supply Chain Management.2003.Vo1.8(2):122-131.

[2] Davood Askarany.Hassan Yazdifar.Saeed Askary.Supply chain management.activity-based costing and organizational factors[J].Production Economics.2010(127):238-248.

[3] Amy Z Zeng.Christian Rossetti.Developing a framework for evaluating the logistics costs in global sourcing[J].Intematioual Journal of Physical Distribution\&Logistics Management.

2003,33(9/10):785-803.

[4] Kimio Uno.Peter Bartelmus.Environmental Accounting in Theory and Practice[M]. Kluwer Academic Publishers. 1995:23-46

[5] Macro Sys Research and Technology, Washington,DC.Logistics Costs and U.S. Gross Domestic Product[R]. August 25, 2005.

[6] Delucchi,M.A,Murphy J. J., and McCubbin D.R. The Health and Visibility Cost of Air Pollution:A Comparison of Estimation Methods[J].Journal of Environmental Manaaement, 2002,64(2). 